\title{
A new interpretation of neutrophil-lymphocyte ratio from psychiatric aspect
}

\author{
Kalelioglu T, Karamustafalioglu N \\ Department of Psychiatry, Bakırköy Mental Health Research and Training State Hospital, Istanbul, Turkey. \\ tevfikkaleli@hotmail.com
}

Text in PDF www.elis.sk.

To the Editor;

Neutrophil-lymphocyte ratio was first defined by Zahorec R. in 2001 as an easy method to evaluate the intensity of inflammation, infection and sepsis. His findings were published in the Bratislava Medical Journal (1). Since then, NLR has been widely studied as a subclinical inflammation marker, as well as that for high-grade inflammation in infection and sepsis (2).

In the past decade, there has been a growing interest in NLR for assessing systemic inflammation in psychiatric disorders. High NLR levels were reported in major depression (3-6), bipolar disorder (7-9), psychotic disorders (10-13), and anxiety-related disorders (14). In all above-mentioned studies, NLR was discussed association with the inflammatory aspect. In this paper, we aimed to point out the explanation of high NLRs in psychiatric studies in an alternative manner.

Autonomic nervous system dysfunction has been considered an underlying mechanism for medical comorbidities in patients with psychiatric disorders (15). The impact of stress and psychiatric conditions on autonomic nervous system is presented as sympathetic and/or parasympathetic dysfunctions (16). Increased sympathetic or decreased parasympathetic activity is manifested as disruption in heart rate parameters. Impaired heart rate variables suggesting high sympathetic and/or low vagal activity have been found in several studies in patients with major depression (17-20), bipolar disorder (21-23), psychotic disorders (24-26) and anxiety related disorders (27).

The brain and the immune system are communicating each other to maintain homeostasis. The autonomic nerve system (ANS) is one of the links between the two systems. The sympathetic nervous system (SNS), a major component of ANS, innervates all lymphoid organs and releases hormones to provide the association between the brain and immune system (28). The two major

Department of Psychiatry, Bakırköy Mental Health Research and Training State Hospital, Istanbul, Turkey

Address for correspondence: T. Kalelioglu MD, Department of Psychiatry, Bakırköy Mental Health Research and Training State Hospital, Istanbul, Turkey

Phone: +902125436565 types of leukocytes, granulocytes and lymphocytes, are affected by autonomic nerve system. Granulocytes including neutrophils are activated in number and function through sympathetic activation whereas parasympathetic stimulation activates lymphocytes (29). As a net effect, the activation of the sympathetic nervous system triggers leukocytosis with a "left shift"(30) which also means an increment in neutrophil-lymphocyte ratio.

Although high NLR rates in psychiatric disorders are considered to reflect an inflammatory status, it may refer an indirect reflection of the ANS's imbalance in favor of SNS activity. Therefore, NLR can be interpreted not only as a marker of inflammation, but also an overlooked marker of increased sympathetic activation.

\section{References}

1. Zahorec R. Ratio of neutrophil to lymphocyte counts--rapid and simple parameter of systemic inflammation and stress in critically ill. Bratisl Lek Listy 2001; 102 (1): 5-14.

2. Zahorec R. Neutrophil-to-lymphocyte ratio. Sixteen-year-long history since publication of our article in Bratislava Medical Journal. Bratisl Lek Listy 2017; 118 (6): 321-323.

3. Atli A, Demir S, Bulut M, Okan İbiloğlu A, Güneş M, Kaya M et al. Neutrophil\&amp; ndash; lymphocyte ratio in patients with major depressive disorder undergoing no pharmacological therapy. Neuropsychiatr Dis Treat 2015; 11: 2253.

4. Aydin Sunbul E, Sunbul M, Yanartas O, Cengiz F, Bozbay M, Sari I et al. Increased Neutrophil/Lymphocyte Ratio in Patients with Depression is Correlated with the Severity of Depression and Cardiovascular Risk Factors. Psychiatry Investig 2016; 13 (1): 121.

5. Özyurt G, Binici NC. Increased neutrophil-lymphocyte ratios in depressive adolescents is correlated with the severity of depression. Psychiatry Res 2018; 268: 426-431.

6. Demircan F, Gözel N, Kılınç F, Ulu R, Atmaca M. The Impact of Red Blood Cell Distribution Width and Neutrophil/Lymphocyte Ratio on the Diagnosis of Major Depressive Disorder. Neurol Ther 2016; 5 (1): 27-33.

7. Çakır U, Tuman TC, Yıldırım O. Increased neutrophil/lymphoctye ratio in patients with bipolar disorder: a preliminary study. Psychiatr Danub 2015; 27 (2): 180-184. 
8. Kalelioglu T, Akkus M, Karamustafalioglu N, Genc A, Genc ES, Cansiz A et al. Neutrophil-lymphocyte and platelet-lymphocyte ratios as inflammation markers for bipolar disorder. Psychiatry Res 2015; 228 (3): 925-927.

9. Mazza MG, Tringali AGM, Rossetti A, Botti RE, Clerici M. Crosssectional study of neutrophil-lymphocyte, platelet-lymphocyte and monocyte-lymphocyte ratios in mood disorders. Gen Hosp Psychiatry 2019; 58: 7-12.

10. Semiz M, Yildirim O, Canan F, Demir S, Hasbek E, Tuman TC et al. Elevated neutrophil/lymphocyte ratio in patients with schizophrenia. Psychiatr Danub 2014; 26 (3): 220-225.

11. Özdin S, Sarisoy G, Böke Ö. A comparison of the neutrophil-lymphocyte, platelet-lymphocyte and monocyte-lymphocyte ratios in schizophrenia and bipolar disorder patients - a retrospective file review. Nord J Psychiatry 2017; 71 (7): 509-512.

12. Kulaksizoglu B, Kulaksizoglu S. Relationship between neutrophil/ lymphocyte ratio with oxidative stress and psychopathology in patients with schizophrenia. Neuropsychiatr Dis Treat 2016; 12: 1999-2005.

13. Özdin S, Böke Ö. Neutrophil/lymphocyte, platelet/lymphocyte and monocyte/lymphocyte ratios in different stages of schizophrenia. Psychiatry Res 2019; 271: 131-135.

14. Özyurt G, Binici NC. The neutrophil-lymphocyte ratio and plateletlymphocyte ratio in adolescent obsessive-compulsive disorder: Does comorbid anxiety disorder affect inflammatory response? Psychiatry Res 2019; 272: 311-315.

15. Alvares GA, Quintana DS, Hickie IB, Guastella AJ. Autonomic nervous system dysfunction in psychiatric disorders and the impact of psychotropic medications: a systematic review and meta-analysis. J Psychiatry Neurosci 2016; 41 (2): 89-104.

16. Berntson G. Electrocardiography JC-D, 2004 undefined. Heart rate variability: Stress and psychiatric conditions. eriehealtheducation.com.

17. Agelink MW, Boz C, Ullrich H, Andrich J. Relationship between major depression and heart rate variability. Clinical consequences and implications for antidepressive treatment. Psychiatry Res 2002; 113 (1-2): 139-149.

18. Udupa K, Sathyaprabha TN, Thirthalli J, Kishore KR, Lavekar GS, Raju TR et al. Alteration of cardiac autonomic functions in patients with major depression: a study using heart rate variability measures. J Affect Disord 2007; 100 (1-3): 137-141.
19. Licht CMM, de Geus EJC, Zitman FG, Hoogendijk WJG, van Dyck R, Penninx BWJH. Association Between Major Depressive Disorder and Heart Rate Variability in the Netherlands Study of Depression and Anxiety (NESDA). Arch Gen Psychiatry 2008; 65 (12): 1358.

20. Brunoni AR, Kemp AH, Dantas EM, Goulart AC, Nunes MA, Boggio PS et al. Heart rate variability is a trait marker of major depressive disorder: evidence from the sertraline vs. electric current therapy to treat depression clinical study. Int J Neuropsychopharmacol 2013; 16 (9): 1937-1949.

21. Chang H-A, Chang C-C, Tzeng N-S, Kuo TBJ, Lu R-B, Huang S-Y. Heart rate variability in unmedicated patients with bipolar disorder in the manic phase. Psychiatry Clin Neurosci 2014; 68 (9): 674-682.

22. Moon E, Lee S-H, Kim D-H, Hwang B. Comparative Study of Heart Rate Variability in Patients with Schizophrenia, Bipolar Disorder, Posttraumatic Stress Disorder, or Major Depressive Disorder. Clin Psychopharmacol Neurosci 2013; 11 (3): 137-143.

23. Voggt A, Berger M, Obermeier M, Löw A, Seemueller F, Riedel M et al. Heart rate variability and Omega-3 Index in euthymic patients with bipolar disorders. Eur Psychiatry 2015; 30 (2): 228-232.

24. Quintana DS, Westlye LT, Kaufmann T, Rustan ØG, Brandt CL, Haatveit B et al. Reduced heart rate variability in schizophrenia and bipolar disorder compared to healthy controls. Acta Psychiatr Scand 2016; 133 (1): 44-52.

25. Akar SA, Kara S, Latifoğlu F, Bilgiç V. Analysis of heart rate variability during auditory stimulation periods in patients with schizophrenia. J Clin Monit Comput 2015; 29 (1): 153-162.

26. Cacciotti-Saija C, Quintana DS, Alvares GA, Hickie IB, Guastella AJ. Reduced heart rate variability in a treatment-seeking early psychosis sample. Psychiatry Res 2018; 269: 293-300.

27. Chalmers JA, Quintana DS, Abbott MJ-A, Kemp AH. Anxiety Disorders are Associated with Reduced Heart Rate Variability: A MetaAnalysis. Front Psychiatry 2014; 5: 80.

28. Elenkov IJ, Wilder RL, Chrousos GP, Vizi ES. The sympathetic nerve - an integrative interface between two supersystems: the brain and the immune system. Pharmacol Rev 2000; 52 (4): 595-638.

29. Abo T, Kawamura T. Immunomodulation by the autonomic nervous system: therapeutic approach for cancer, collagen diseases, and inflammatory bowel diseases. Ther Apher 2002; 6 (5): 348-357.

30. Gurrera RJ. Sympathoadrenal hyperactivity and the etiology of neuroleptic malignant syndrome. Am J Psychiatry 1999; 156 (2): 169-180.

Received April 16, 2019. Accepted May 7, 2019. 